\title{
AN EFFECT OF MICROSTRUCTURE DEFECTS ON FATIGUE RESISTANCE OF GLASS FIBRE REINFORCED POLYMER COMPOSITES USED FOR SPRINGS OF FREIGHT VEHICLES
}

Fatigue properties of glass reinforced polymer (GRP) composite materials and advanced components manufactured using GRP are discussed with an emphasis on scale and microstructure effects. Results of an experimental investigation of fatigue damage mechanisms under bending and shear cyclic loading and effects of microstructural defects resulting from an insufficient resin wet out are presented and analysed. It was shown that if microstructural defects are present in the component, initiation of fatigue damage is localised into these areas, resulting in sudden, premature failure. Fatigue life can be then reduced by more than three orders in comparison with the perfect material. The presence of defects is affected particularly by properties of the constituents and moulding parameters. Suitable changes of the process parameters resulted in a significant improvement of fatigue resistance.

\section{Introduction}

Characteristic properties of long fibre glass reinforced polymers (GRP) composites like low specific weight, high strength and generally very good fatigue resistance enable one to use these materials in heavy-duty light-weight structures, like aircraft components or wind turbine blades. In additions, low E-modulus together with internal damping and low dynamic stiffness make GRP composites suitable for the manufacture of road-friendly leaf springs and suspensions including those for high capacity trailers and railway freight vehicles. The low E-modulus in comparison with steel is a very important characteristic enabling the introduction of a new design philosophy for springs, suspensions and bogies. In case of springs, it is possible to use just one or two leaves with stable damping properties and other characteristics during the whole service life. In addition, due to the low specific weight, a $60 \%$ reduction of the whole suspension weight can be obtained by replacing steel spring with composite springs with the same function. This is particularly important because springs represent unsprung mass. An efficient noise damping is an additional, but very important feature of GRP materials making suspensions more environmentally friendly. All these properties are the reason, why the design and characterisation of glass fibre reinforced composites have received recently a great amount of interest [1-3]

In comparison with metals, the use of GRP composites has specific difficulties. Due to the material heterogenity, any change of shape and size of a component can affect its mechanical properties and so, changes have to be experimentally verified. If process parameters are not correctly or other characteristics of the constituents like glass preforms are not perfectly maintained or incorrectly selected, various kinds of defects can arise, like bubbles, voids, porosity or insufficient wet out. These defects can fundamentally reduce static and fatigue strength [4-5].

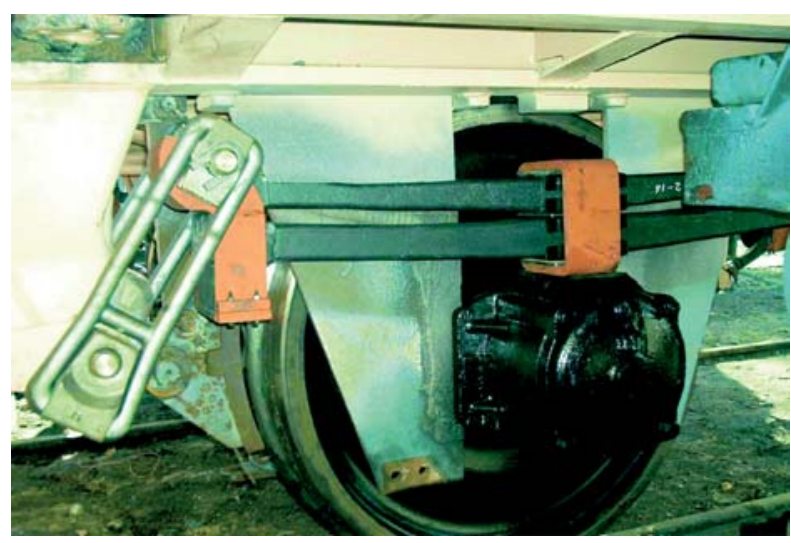

Fig. 1 GRP spring with new type of shackles on a new Czech wagon during fit test

Within an on-going European research and development EUREKA project Eurobogie, significant progress has been reached in the field of an innovative design and manufacture of GRP springs for railway freight vehicles to replace traditional multi-leaf steel springs. The prototype of GRP railway spring together with a new type of shackles Niesky I during a fit test on a new Czech wagon is shown in Fig. 1.

To ensure the requested high reliability and safety of springs, a large number of static and fatigue tests on components besides a detailed material characterisation was carried out. In the paper, results of fatigue tests of the full-scale components are described, analysed and compared with the results obtained on small laboratory specimens with particular emphasis on the material microstructure and presence of defects.

\footnotetext{
* Ivo Černý ${ }^{1}$, Rayner M. Mayer², Ivan Fürbacher ${ }^{1}$

${ }^{1}$ SVUUM a.s., Areál VÚ 565, CZ-19011 Praha 9, Czech Republic, E-mail: strenght@svum.cz, Ivo.Cerný@seznam.cz

${ }^{2}$ Sciotech Ltd., 9 Heathwood Close, Yateley, GU46 7TP, U.K.
} 


\section{Experiments}

Fatigue tests were performed on completely assembled twoleaf springs. Both the leaves were made from glass fibre reinforced polyester (Scott Bader Crystic PD9229) and manufactured by a vacuum assisted resin transfer technology by EM Fiberglas. The reinforcing E-glass rovings (Vetrotex P192) are assembled using knitting machinery to form a unidirectional glass tape of constant width (Culzean Textile Solutions). This consists of $97 \%$ glass in the longitudinal direction and $3 \%$ in the transverse direction. The top leaf has parabolic thickness characteristic by a constant bending stress. The parabolic shape is achieved by cutting suitable core layers to length. These are then heat set to produce a preform glass tape pack. The glass fibre volume fraction of the springs is about $65 \%$. The total mass of the two GRP leaves is $26 \mathrm{~kg}$ giving a total suspension mass of $38 \mathrm{~kg}$, compared with $120 \mathrm{~kg}$ for the UIC 22.5 tones parabolic steel suspension. The material properties of the unidirectional composites were measured at RIS $\varnothing$ National Laboratory [6]. Basic mechanical properties are: bending stiffness and strength about $35 \mathrm{GPa}$ and $1000 \mathrm{MPa}$, respectively, static interlaminar shear strength $50 \mathrm{MPa}$. The experimental programme included fatigue tests performed on $3 \mathrm{~PB}$ specimens, too. All the tests carried out in [6] were performed on specimens taken from a bottom leaf section without defects, which was checked using ultrasonic nondestructive testing.

Fatigue load amplitude during full-scale spring tests corresponded to the recommendations of railway standard UIC 517 or to the requirements of Czech Railways, respectively. The former case defines the static load to correspond to the maximum static operation loading, which is $105 \mathrm{kN}$ for the 22.5 tones axle, and load amplitude $\pm 25 \%$ of the static load. In the latter case, the static load is the same, but load amplitude is $\pm 30 \%$. The requested number of cycles to failure should not be less than one million. In both the cases, springs have to be attached by pins going through eye ends on carriages enabling free horizontal motion. Load frequency was $1.2 \mathrm{~Hz}$.

From the material point of view, the full-scale spring tests can be evaluated as tests of single large bending specimens of the maximum thickness $52 \mathrm{~mm}$, width $115 \mathrm{~mm}$ and test span $1190 \mathrm{~mm}$. It was calculated that actual stress in the top leaf, if loaded separately without the bottom leaf, corresponds almost exactly to 50\% of the loading used for the whole component within the precision better than $2 \%$. This calculation was also experimentally verified [7].

An additional group of fatigue tests to study scale effects was performed on small 3PB specimens taken and manufactured from two randomly selected leaves, top and bottom, without any non destructive (NDE) testing, unlike the fatigue material characterisation tests in [6]. Dimensions of 3PB specimens were selected to ensure the same type of loading as in actual leaves representing the large specimens, namely thickness $5.2 \mathrm{~mm}$ and test span $120 \mathrm{~mm}$. These dimensions resulted in the same ratio of bending and interlaminar shear cyclic stresses, respectively. Width of these specimens was $25 \mathrm{~mm}$, load frequency was between 35 and $40 \mathrm{~Hz}$.

\section{Results and discussion}

Results of all fatigue tests are summarised and mutually compared in Fig. 2. There are four different groups of data: (i) full-scale tests of complete springs evaluated and recalculated as fatigue tests of individual top leaves representing large specimens, (ii) tests of small 3PB specimens taken from randomly selected top and bottom leaves without non-destructive inspection, (iii) results of fatigue tests of small 3PB specimens cut from a bottom leaf with an almost perfect microstructure as examined by ultrasonic method [6], recalculated in terms of stress amplitude and (iv) two experimental points of fatigue tests of GRP trailer springs made from a similar material and by a similar process, with a good microstructure $[8,9]$

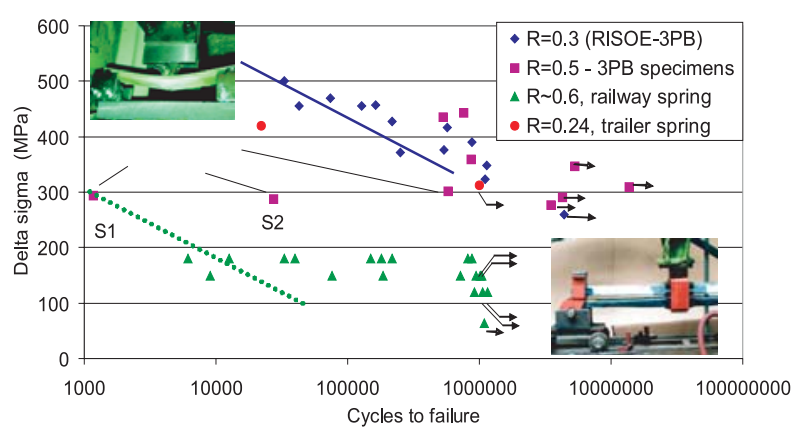

Fig. 2 Comparison of bending fatigue tests results of material coupons and springs

The results of fatigue tests of full-scale GRP railway springs look to have a large scatter. Actually, it is not a scatter but a systematic dependence corresponding to the process of gradual improvement of numerous manufacturing parameters like changes of preform tool, preform lay-up, number and position of injection channels in the mould, catalyst, accelerator, inhibitor, time of vacuum operation and injection time. Unlike the first tested group of GRP springs with fatigue life bellow 100000 cycles, when the parameters were not optimised, and springs with just partially optimised parameters with a medium fatigue life between 100000 and 200000 cycles, springs manufactured with quite optimum parameters have acceptable fatigue life of more than 1 million cycles. However, the general potential of the excellent fatigue resistance of GRP material still has not been fully reached.

When the first group of full-scale tests of the railway springs was performed, premature failures bellow 100000 cycles were rather surprising, considering the very good fatigue resistance results obtained on small 3PB specimens tested at the RIS $\varnothing$ National Laboratory. To find causes of the premature failure, detailed microstructure analyses of central areas of broken top leaves were carried out. It followed from the failure mode that interlaminar shear fatigue resistance was particularly poor as all railway springs broke suddenly by one or two interlaminar shear cracks passing along the length of the leaf near its neutral axis, near the centre plane with zero bending stress but maximum shear stress. Examining the microstructure, large areas of very poor wet out were found 
in all leaves with the premature failure. An example of an insufficiently wetted area with quite large voids is in Fig. 3.

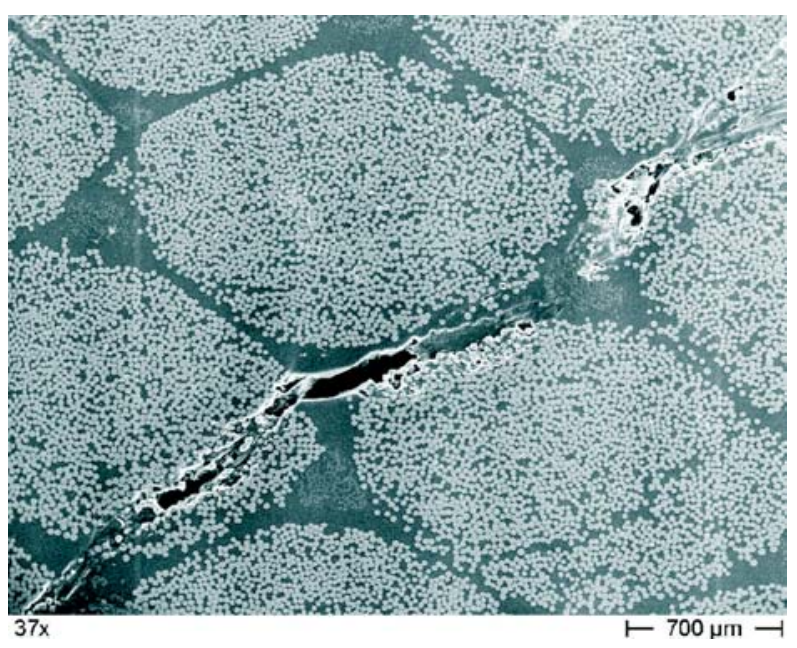

Fig. 3 Voids arisen from insufficient wet out initiating shear fatigue cracks in resin between yarns

As regards the third group of fatigue tests, namely $3 \mathrm{~PB}$ specimens tested at SVÚM a.s., taken from a top and bottom leaf, respectively, randomly selected, not checked by NDT methods, it is clear that most of fatigue results of this group (Fig. 2) correspond quite well to the results obtained at RIS $\varnothing$ National Laboratory on $3 \mathrm{~PB}$ specimens with a perfect microstructure. On the other hand, two specimens, marked S1 and S2 in Fig. 2, had a significantly reduced fatigue life. The reason was the microstructure. In the central areas of specimens S1 and S2, voids and poor wet out was found, unlike the other specimens of this group, where the microstructure was quite good. Not only fatigue life, but also failure mode was different. Specimen S1 broke suddenly, along the central plane of maximum shear but zero bending stress, unlike the specimens with the good fatigue resistance, when failure occurred by a gradual progressive reduction of bending stiffness (Fig. 4) connected with a continuous damage development in a significant volume of the specimen material in the area of tension stresses (Fig. 5).

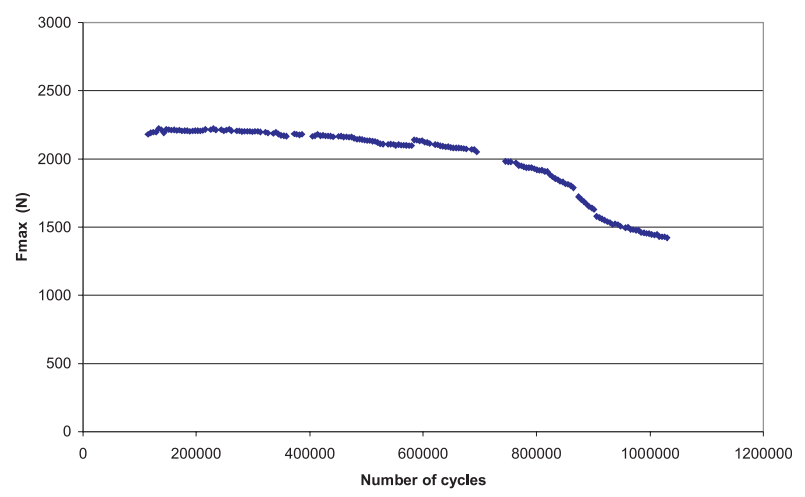

Fig. 4 Example of continuous stiffness changes during 3PB fatigue loading of specimens with good fatigue resistance

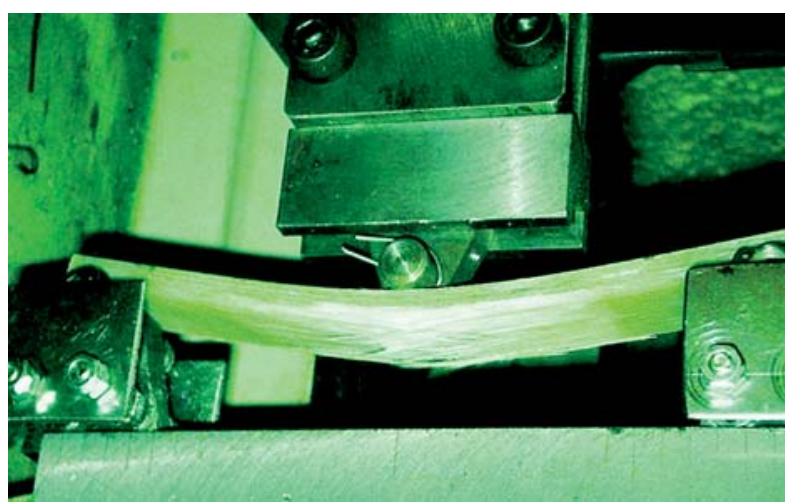

Fig.5 Typical damage development in area of tensile stresses in big material volume of $3 P B$ specimens with good fatigue resistance

It follows from Fig. 2 that fatigue resistance of the worst specimen S1 corresponds almost exactly to the worst results obtained during full-scale testing of actual springs. If a regression line parallel to that of $3 \mathrm{~PB}$ specimens with a good microstructure is drawn, passing through the S1 point, this line corresponds to the worst results of actual spring tests. This effect can be explained by a different probability of an occurrence of harmful voids in fullscale leaves and in small specimens made from them, respectively. Most of the 3PB specimens of the third group were evidently taken from areas of the leaves with a good microstructure. Then the fatigue life corresponded to the results obtained at RIS $\varnothing$ [6]. Just two specimens were randomly taken from areas with the insufficient wet out. Their fatigue resistance was lower by two or three orders in comparison with the specimens with perfect microstructure.

As regards full-scale leaves, the probability of an occurrence of microstructure defects is small, if the manufacturing process allows all air to be excluded and sufficient time for all the glass filaments inside the bundles (4800 tex) to be wet out. High cycle fatigue damage of GRP composites, unlike metals, is quite a global process, connected with gradual changes of stiffness. However, in case of a defect occurrence, fatigue cracking starts in the weakest points of the microstructure and is therefore strongly localised. Then the global stiffness remains almost constant. When the fatigue

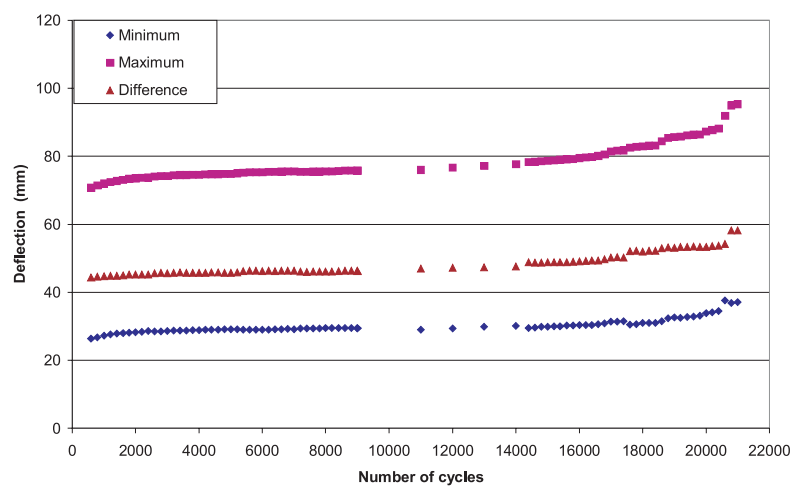

Fig.6 Sigmoidal change of deflection typical for GRP composites with good microstructure during fatigue test of trailer spring in bending. 
crack is locally initiated, it causes a sudden break by interlaminar shear.

In comparison with railway springs, the fatigue resistance of GRP trailer springs in Fig. 2 was very high. Hereat, dimensions of the trailer springs affecting shear stresses, namely maximum thickness and span distance, $58 \mathrm{~mm}$ and $1040 \mathrm{~mm}$, respectively, were very similar to those of railway springs. With the load range of $15-65 \mathrm{kN}$ corresponding to the maximum bending stress range of $312 \mathrm{MPa}$, fatigue life was more than 1 million cycles without failure, which is fully comparable with fatigue tests of the small $3 \mathrm{~PB}$ specimens. When the load amplitude was subsequently raised to the value 22-89 kN, corresponding to the bending stress range $420 \mathrm{MPa}$ fatigue life was 22000 cycles to failure. This very good fatigue resistance was connected with a different failure mode - no sudden break, but continuous damage accumulation in a big material volume (Fig. 6).

\section{Conclusions}

An experimental programme was carried out with the aim to characterise fatigue properties of advanced leaf springs for railway freight vehicles made from long-fibre glass reinforced polyester composite. The programme comprised (i) bending fatigue tests of small specimens taken from a good quality spring to characterise the material, (ii) fatigue tests of whole springs representing large samples and (iii) bending fatigue tests of small specimens randomly taken from actual spring leaves, where the quality was not checked by any NDE method. A comparison with trailer springs manufactured by a similar technology within a previous project was made. The results can be summarised as follows:
- Fatigue strength of the first series of full-scale railway springs was quite poor and did not correspond to the excellent fatigue resistance of small specimens with a good microstructure. Fatigue life of components was lower by more than three orders.

- Most specimens randomly taken from the actually manufactured springs of rather low quality had very good fatigue resistance, corresponding to those specimens used for the basic fatigue material characterisation. However, fatigue life of several specimens of this group corresponded to the premature failure of the worst group of components.

- The main reason for the insufficient fatigue life of components was a presence of voids and bubbles resulting from an insufficient wet out. If small specimens were taken from areas with no defects, their fatigue life was excellent. On the contrary, small specimens with the poor fatigue properties contained microstructural defects as they were taken from insufficiently wetted areas.

- After improving the processing and lay up of the constituents, fatigue resistance was significantly increased and satisfied conditions of railway standards. On the other hand, a comparison with fatigue strength of trailer springs evaluated in the past indicated that there still may be additional fatigue strength to be attained and some further improvements may be reached resulting in negligible differences between fatigue strength of good specimens and full-scale components.

\section{Acknowledgements}

The work has been carried out within the project EUREKA E! 1841 Eurobogie, supported by the Czech Eureka grants OE 148 and OE 44/2 and by UK Department of Trade and Industry. The authors appreciate discussions with many colleagues including Aage Lystrup of RIS $\varnothing$ National Laboratory.

\section{References}

[1] HARRIS, L. R.: Composite leaf spring design. GKM Technology report, August, 1990.

[2] CHAPLIN, C. R., MAYER, R. M., REZAKHANLOU, R.: A new approach to composite leaf springs. Proc. of the conf. Autotech, Birmingham, 1995

[3] CHIANUMBA, A., JERONIMIDIS, G., MAYER, R. M.: Advanced vehicle suspensions using glass reinforced plastics. Proc. $6^{\text {th }}$ European Congress on Lightweight and Small Cars: The Answer to Future Needs, Cernobbio, Italy; 1997, A2.11108: 549-558.

[4] STONE, D. E. W., CLARKE, B.: Non-destructive determination of the void content in carbon fibre reinforced plastics by measurement of ultrasonic attenuation. RAE Tech. Report 74172, 1974

[5] RHEILÄNDER, J. T., NIELSEN, S. A., BORUM, K. K., GUNDTOFT, H. E.: NDE of polymeric composites: A comparison of techniques. Proc of the $18^{\text {th }}$ Risoe Int. Symposium on Materials Science, Ed. Andersen S.I. et. al., RIS $\emptyset$ National Laboratory, Roskilde, Denmark, 1997, pp. 101-125.

[6] LYSTRUP, A., BORUM, K., BRØNDSTED, P.: Mechanical properties and characterisation of GFRP material from train bottom spring No. 01-02-16. Eureka Eurobogie project E!1841 report RISØ-I-2094(EN), November 2003, Roskilde, Denmark

[7] JARRIER, E., MAYER, R. M.: Manufacturing improvements and testing of leaf springs. Eureka Eurobogie project E! 1841 report, Sciotech Projects, Reading University, August 2005

[8] ČERNÝ, I., FÜRBACHER, I., MAYER, R. M.: Possibilities of use of springs made from long-fiber glass reinforced composites in the suspensions of road and rail freight vehicles. Key Engng. Materials, Vols. 230-232, pp.251-254.

[9] ČERNÝ, I., FÜRBACHER, I., MAYER, R. M.: Possibilities of use of springs from composite materials in suspensions of railway freight wagons. Proc. of the $14^{\text {th }}$ Int. Conf. "Current Problems in Rail Vehicles - PRORAIL", Žilina, 6.-8. 10. 1999, Vol. 1, pp.49-56 